\title{
Lexical decision in sentences: Effects of syntactic structure
}

\author{
BARTON WRIGHT and MERRILL GARRETT \\ Massachusetts Institute of Technology, Cambridge, Massachusetts
}

\begin{abstract}
A lexical decision paradigm was used to examine syntactic influence on word recognition in sentences. Initial fragments of sentences were presented visually (CRT display) one word at a time (at reading speeds), from left to right. The string terminated with the appearance of a lexical decision target. The grammatical structure of the incomplete sentence affected lexical decision reaction time (RT). In Experiment 1, modal verb contexts followed by main verb targets and preposition contexts followed by noun targets produced lower RTs than did the opposite pairings (i.e., modal/noun and preposition/verb). In Experiment 2, transitive verb contexts followed by noun targets and subject noun phrase contexts followed by verb targets yielded lower RTs than did the opposite pairings. Similar contrasts for adjective targets did not yield comparable effects in Experiment 2, but did when the adjective was the head of a predictable phrase (Experiment 4). In Experiment 3, noun targets yielded lower RTs than did verb targets after contexts of a transitive verb followed by a prepositional phrase. An account of these effects is offered in terms of parsing constraints on phrasal categories.
\end{abstract}

Real-time language processes, visual or auditory, must associate lexically specified, syntactically and logically organized representations with linguistic stimuli. Such representations provide the bases for interpretation of the utterances or inscriptions that mediate the normal communicative uses of language. Basic human language processing theories must provide an account of the mental operations underlying such an analysis of sentence form, and, in particular, of the relations among lexical, syntactic, and interpretive processes.

A fundamental question of this latter type is that of the relation between word-recognition processes and the processes that assign syntactic organization and semantic interpretation to sentences. We will discuss some of the issues that bear on this question and report experimental results showing effects of syntactic structure on word-recognition processes; these effects can be distinguished from normally correlated interpretive constraints.

It has been widely observed that recognition performance for word strings is better for syntactically and semantically organized sequences than for random

This research was conducted while the first author was supported by an NSF graduate fellowship and an NIMH training grant; experimental support was also contributed by the MIT Center for Cognitive Science under a grant from the Sloan Foundation Particular Sciences program. The experiments reported are part of the doctoral dissertation of the first author. Thanks are due many, in particular to Edward Walker for his encouragement and valuable advice throughout the research, and Sean True for important software support. Requests for reprints should be addressed to: Merrill Garrett, Department of Psychology, Room E10-034, MIT, Cambridge, Massachusetts 02139. strings (e.g., Forster, 1970; Miller, 1962; Miller \& Isard, 1963), and it has often been suggested, although never clearly demonstrated, that recognition for words in sentence context is superior to recognition for words in isolation.

Although the putative effects of semantic and syntactic constraints on word recognition are conceptually separable, and various experimental results show effects of each when the other is absent or nonsupportive (anomalous) (e.g., Miller, 1962; Miller \& Isard, 1963), most recent experimental demonstrations of contextual influence on word recognition-for example, as indexed by lexical decision performance for nondegraded stimuliconfound syntactic and semantic influences (see, e.g., Fischler \& Bloom, 1980, and Forster, 1981). Those few experiments that have focused specifically on the question of syntactic influence on lexical search and selection either have had negative results (e.g., Forster \& Bednall, 1976; Siedenberg, Tanenhaus, Leiman, \& Bienkowski, 1982; Prather \& Swinney, Note 1), or have reported rather fragile effects dependent on blocked presentation (Fay, 1975; Goodman, McClelland, \& Gibbs, 1981). Effects in the latter two reports are apparently the consequence of strategies adopted by subjects in these lexical decision tests. ${ }^{1}$

This apparent marginal and strategy-based status of syntactic constraints on word recognition is sharply at variance with the strong indications that syntactic processing itself is quite reflexive-subjects analyze syntactic forms even when such analysis is irrelevant to their task (Forster, 1979) and even when the redundant syntactic variations are known to them in advance of testing. Furthermore, the findings of a minimal syntactic role in word recognition do not square well with the 
plausible expectation that word-recognition processes should be tailored to the demands of parsing systems. Given that a primary data source for parsing procedures is the lexical sequence representing the sentence, it would be rather remarkable if no concession to this role were manifest in the word-recognition system-that is, if the nomination or selection of readouts from the lexical inventory were independent of the syntactic roles of the input word.

It is, of course, conceivable that the powerful facilitatory effects on performance that are associated with sentence organization in general and syntax in particular do not lie in directing primary contact with the lexical inventory, but rather in filtering the products of basic lexical recognition processes, selecting those to be integrated into the current structural analysis and passed on for interpretive processes and possible retention.

This conception of the role of syntactic organization on word recognition suggests that it is an inhibitory effect-that is, that the response times (RTs) for syntactically inappropriate recognition targets are increased. This view comports with the results from priming experiments showing that the syntactically inappropriate reading of an ambiguous lexical item is, in fact, activated (Seidenberg et al., 1982; Prather \& Swinney, Note 1; Oden \& Spira, Note 2; see also Swinney, 1983). Such results indicate that syntactic constraints do not determine which of the lexical entries that are compatible with a given orthographic or acoustic input description are contacted, although they leave open the possibility that the speed with which such contact is made is affected.

In order to address issues of this sort, one needs some indication of a systematic effect of syntactic context on lexical processing. We report here a robust effect of specifically syntactic roles on word recognition as assessed by lexical decision performance. We interpret this effect as one of relative ease of parsability for the syntactic structures that yield contrasting syntactic roles for the target words.

\section{EXPERIMENT 1}

The purpose of this experiment was to determine whether a reliable syntactic influence on lexical decision could be discovered. Each stimulus item consisted of an initial portion of an English sentence terminating in a lexical decision target. The sentence fragment preceding the target will be called the context string. Example 1 shows a quadruple of items, consisting of a pair of context strings crossed with a target word pair:

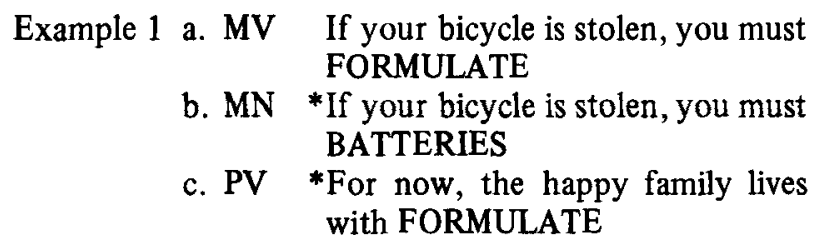

d. PN For now, the happy family lives with BATTERIES

In Example 1a, the context string ends in a subject noun phrase, followed by a modal verb. It is easy to continue this fragment with a main verb, such as FORMULATE, but virtually impossible to continue it with a plural noun, such as BATTERIES. (The asterisks before Examples $1 \mathrm{~b}$ and $1 \mathrm{c}$ signify that the context strings cannot be grammatically continued with the target word.) If the readiness with which a word can be assimilated to the syntactic structure of the preceding fragment does affect lexical decision [i.e., readiness to accept a verb (FORMULATE) after a modal as opposed to a noun (BATTERIES)], we would expect the RTs for MV cases, such as Example 1a, to be lower than those for MN cases, such as Example 1b. Correspondingly, for the context string ending in a preposition, the prediction for the same pair of target words is reversed: Example 1c cannot be readily continued with an uninflected verb, such as FORMULATE, but can continue with a plural noun, such as BATTERIES. Hence, RTs for PN versions, such as Example 1d, should be lower than those for PV versions, such as Example 1c.

The experiment consisted of two subexperiments (Experiments 1a and 1b); Experiment $1 \mathrm{~b}$ was a replication of Experiment 1a, but using different stimulus items. For all stimulus items used, note that the syntactically appropriate members of the target word pairs are not more predictable on semantic grounds than are the syntactically inappropriate members; both types of target words have zero predictability.

\section{Method}

Subjects. Twenty MIT undergraduate volunteers were paid for their participation. All were native speakers of English, with normal (corrected) vision. Ten subjects were run in each of Experiments $1 \mathrm{a}$ and $1 \mathrm{~b}$, five in each context string $\mathrm{x}$ target type condition for each subexperiment. Four subjects in Experiment $1 \mathrm{a}$ and two in Experiment $1 \mathrm{~b}$ were replaced due to their having mean RTs greater than $850 \mathrm{msec}$ or RT standard deviations greater than $300 \mathrm{msec}$. None exceeded the $10 \%$ error criterion. RTs more than two standard deviations above the subject's mean were replaced with that subject's cutoff value.

Materials. The complete set of Experiment 1 materials with word targets is shown in Appendix A. The quadruple in Example 1 is typical. Twelve such quadruples were constructed, each consisting of a pair of context strings crossed with a pair of target words. One member of each context string pair ended in a modal verb, and the other ended in a preposition; they ranged in length from 5 to 12 words. Items in any given quadruple were matched for length in words, and approximately matched for typed length (i.e., the total number of characters was matched).

Each pair of target words consisted of a verb and a plural noun. All verbs and nouns were unambiguous as to grammatical category. ${ }^{2}$ The noun and verb in each pair were matched for length in letters and syllables, and approximately for frequency of occurrence in written English, according to the KuceraFrancis (1967) count. Target words ranged in length from five to nine letters.

Nonword target pairs that conformed to normal orthographic conventions were constructed. The "noun" nonwords ended in 
$[-\mathrm{s}]$, and the "verb" nonwords did not end in [-s]. These nonword pairs were assigned to 12 different pairs of context strings that were designed according to the same criteria as the experimental items with real-word targets. In Experiment $1 \mathrm{~b}$ (the replication), the word targets were assigned to this group of context strings, and the nonwords were assigned to those with word targets in Experiment 1a. Thirty filler items in which the target words were a natural continuation of the context string were constructed. In 24 of these cases, the target word also completed a sentence of English. Example filler items are shown in Example 2:

Example 2 a. There are six churches in this small TOWN

b. As the man fell down the stairs, he broke his GLASSES

c. Good raisins are dried in the sun PATIENTLY

d. At noon the whistle in the factory went OFF

c. At the same time we must not forget OUR

An additional 30 filler items, of similar construction but with nonword targets, were included to maintain a balance of word and nonword items. ${ }^{3}$

The materials were grouped into two sets to be seen by two different groups of subjects. For each quadruple of experimental items, versions MV and PN were presented to one subject group, and versions $P V$ and $M N$ were presented to the other. This was counterbalanced so that each subject saw the four item types equally often. The items were arranged in a single pseudorandom order (by context string) for both subject groups. The 132 items of the experiment were divided into two equal blocks, and were preceded by 12 representative practice items.

Procedure. The subject was seated before the CRT of a Terak computer in a dimly lit room; he or she held a small box with two side-by-side microswitches. The subject operated one switch with each hand, the right for word responses and the left for nonword.

A fixation cross appeared at the left margin of the CRT before each trial. At the start of the trial, the fixation mark disappeared, and the context string appeared from left to right across the screen, a new word appearing every $200 \mathrm{msec}$ ( 300 words $/ \mathrm{min}$ ). One hundred milliseconds after the appearance of the last word of the context string, a brief tone sounded; $300 \mathrm{msec}$ after the tone onset, the target word appeared at the right of the last word in the context string, in capital letters. The context string and target word remained on the screen until the subject made his or her lexical decision. There were thus three cues indicating the target word: the tone $300 \mathrm{msec}$ before its appearance, a minor delay in its appearance ( $400 \mathrm{msec}$ rather than $200 \mathrm{msec}$ after the previous word), and the uppercase letters.

The RT and response (yes or no) were recorded with millisecond accuracy and stored automatically by the computer. The presentation of items was self-paced by the subject via a foot pedal, although a minimum of 1 sec separated trials.

The subjects were instructed in the procedure and the nature of the lexical decision task. They were informed that some target words would fit with the preceding sentence and some would not, but it was emphasized that they should not concern themselves with such differences. The subjects received no feedback on their performance.

\section{Results and Discussion}

The error rates (including filler items) were $3.1 \%$ in Experiment 1a and 4.5\% in Experiment $1 \mathrm{~b}$. Among conditions, no differences approached significance. (The percentages differed substantially, but the absolute number of errors was small.) Table 1 shows the RT and error results for word targets in Experiment 1.
Table 1

Mean Reaction Times (RTs) (in Milliseconds) as a Function of Syntactic Category of Target and Context-Final Word

\begin{tabular}{|c|c|c|c|c|c|}
\hline \multirow{3}{*}{$\begin{array}{c}\text { Context-Final } \\
\text { Word } \\
\end{array}$} & \multicolumn{4}{|c|}{ Target } & \multirow[b]{3}{*}{ Mean } \\
\hline & \multicolumn{2}{|c|}{ Verb } & \multicolumn{2}{|c|}{ Noun } & \\
\hline & $\mathrm{RT}$ & PE & $\mathrm{RT}$ & $\mathrm{PE}$ & \\
\hline \multicolumn{6}{|c|}{ Experiment 1a } \\
\hline $\begin{array}{l}\text { Modal } \\
\text { Preposition }\end{array}$ & $\begin{array}{l}652 \\
696\end{array}$ & $\begin{array}{r}10 \\
7\end{array}$ & $\begin{array}{l}707 \\
669\end{array}$ & $\begin{array}{l}3 \\
2\end{array}$ & $\begin{array}{l}679 \\
681\end{array}$ \\
\hline Mean & 674 & & 688 & & \\
\hline \multicolumn{6}{|c|}{ Experiment $1 \mathrm{~b}$} \\
\hline $\begin{array}{l}\text { Modal } \\
\text { Preposition }\end{array}$ & $\begin{array}{l}668 \\
738\end{array}$ & $\begin{array}{l}3 \\
7\end{array}$ & $\begin{array}{l}718 \\
668\end{array}$ & $\begin{array}{r}3 \\
12\end{array}$ & $\begin{array}{l}693 \\
703\end{array}$ \\
\hline Mean & 703 & & 693 & & \\
\hline
\end{tabular}

Note $-P E=$ percent error.

The predicted result was that the syntactically legal continuations in versions MV and PN would produce shorter RTs than would the two syntactically illegal versions (MN and PV). This prediction was supported. The interaction in a $2 \times 2$ analysis of variance ${ }^{4}$ was significant in Experiment 1a $\left[\min F^{\prime}(1,18)=4.90\right.$, $\mathrm{p}<.05]$ and approached significance in the replication $\left[\min F^{\prime}(1,17)=3.52, p<.10\right]$. Neither main effect approached significance. Note that the replication was not only a replication over subjects. Although the particular target words were the same, the context strings and the particular pairing of context string with target words were completely different in Experiments la and $1 b$. If the results of the initial and replication experiments were combined, the interaction effect was stronger $\left[\min F^{\prime}(1,34)=7.62, p<.01\right]$, but the main effects were still far from significant.

The results of Experiment 1 demonstrate quite simply a strong effect of syntactic environment on a lexical decision target. Modal verbs engendered faster decision times for verbs; prepositions engendered faster times for nouns. This held even when the sentence context bore no useful relation to the meaning of the particular verb or noun target.

\section{EXPERIMENT 2}

Three issues were addressed: (1) possible effects of semantic differences between nouns and verbs; (2) the generality of syntactic context effects; and (3) effects of grammaticality versus ease of analysis.

The target word pairs of Experiment 1 were matched for length, frequency, and number of syllables. However, they also differed in a host of other ways, including their meanings and uses in the language. To make a stronger case that the effects observed with this paradigm arose from syntactic rather than interpretive differences, target word pairs such as TRANSLATES/ TRANSLATION were used in Experiment 2. In an 
important sense, these are the same word, differing only in the suffixes that determine their parts of speech. ${ }^{5}$

Instead of using modal verbs and prepositions as the final words of the context strings, nouns and verbs were used. In particular, each noun was the last word in a singular subject noun phrase, and each verb was the main verb of a tensed clause. Verbs that usually take a direct object were used. When crossed with the target word pairs, quadruples such as Example 3 result:

Example 3 a. NV The crowd near the church indicates that an important funeral TRANSLATES

b. NN ?The crowd near the church indicates that an important funeral TRANSLATION

c. VV *The towers on the horizon indicate that the barriers isolate TRANSLATES

d. VN The towers on the horizon indicate that the barriers isolate TRANSLATION

Version $\mathrm{NN}$ is of particular interest. A noun often can be followed by another noun, as can be seen in another possible continuation of $\mathrm{NN}$, "The crowd near the church indicates that an important funeral PROCESSION (is about to leave)." The first noun functions as an adjective, although this construction is so productive that one would not want to say that FUNERAL is an adjective as well as a noun. The NN version is thus not syntactically illegal. But we might suspect a possible parsing preference for a verb after FUNERAL, that is, that an NV analysis would be more likely (ranked before) an NN analysis. This NV-NN comparison permits us to differentiate between two legal cases that human parsers routinely handle. In Experiment 1, the paradigm was called upon to distinguish only grammatical from ungrammatical sentence continuations.

In sum, we would predict the decision times for versions $\mathrm{NV}$ and $\mathrm{VN}$ to be less than those for versions VV and NN. Those for version NN might be somewhat faster than those for version VV because of version NN's greater acceptability.

Experiment 2 also broadened the repertoire of target word categories. The very same context strings ending in nouns and verbs were paired with adjective and adverb targets, to yield quadruples such as Example 4:

Example 4 a. NA *The crowd near the church indicates that an important funeral HAPPY

b. NR The crowd near the church indicates than an important funeral HAPPILY

c. VA The towers on the horizon indicate that the barriers isolate HAPPY d. VR The towers on the horizon indicate that the barriers isolate HAPPILY

Version NA is difficult to complete syntactically (only an object relative clause with a deleted relative pronoun can be used), and thus should yield a longer RT than would the other three versions, which are easy to complete.

The nonword foils associated with the above materials were designed to allow a systematic look at whether sentence context constraints interact with the morphological marking of category for nonwords. The same kind of context strings were followed by matched nonword pairs such as FABLORATES/FABLORATION and SERICAL/SERICALLY, each of which is marked by suffixes indicating its part of speech.

\section{Method}

Subjects. Forty MIT undergraduate volunteers were paid for their participation; 10 were in each condition. All were native speakers of English, and none had participated in Experiment 1. Eight subjects were replaced due to having error rates greater than $10 \% ; 10$ were replaced due to producing mean RTs greater than $850 \mathrm{msec}$ or RT standard deviations greater than $250 \mathrm{msec}$.

Materials. The entire set of Experiment 2 materials appears in Appendix B. Twelve quadruples like Example 3 were constructed, each consisting of a context string pair and a target word pair. One member of each context string pair ended in a noun; the other ended in a verb. In particular, the noun would naturally be construed as ending a singular noun phrase serving as the subject of its clause. The verb was always the main verb of a tensed clause, and verbs that require noun objects were chosen. The two context strings in a pair were matched rather closely for length, overall grammatical structure, and characteristics of the final words.

Twelve verb/noun target word pairs were constructed, the noun having been derived from the verb by addition of a derivational suffix. The verb occurred in its third-person-singular form, inflected with an [-s]. Both members of all pairs were unambiguous as to grammatical category. Pairs were also carefully selected so that they shared all of their meanings. Matching for frequency proved impossible, since derived nouns are nearly always less frequent than their base verbs. The ratio of verb to noun frequencies (summed over inflections) was approximately 2:1 for all pairs. The nouns were generally longer than their corresponding verbs, in number of letters and number of syllables.

The very same 12 context string pairs were combined with 12 adjective/adverb pairs, creating items such as are shown in Example 4. The adverb in each pair was formed from the adjective by adding the [-ly] morpheme. Both members of each pair were unambiguous as to grammatical category. As with the verb/noun pairs, the adjective and adverb shared all their meanings. Frequency matching was again impossible. The adjectiveto-adverb frequency ratio was roughly $3: 1$.

For each of the 12 context string pairs, there were a total of 8 versions, 4 with verb/noun targets (as in Example 3) and 4 with adjective/adverb targets (as in Example 4). These items were shown to four subject groups in a counterbalanced design. Each subject saw a particular context string only once, and only one member of a target word pair. No subject saw both TRANSLATES and TRANSLATION, for instance. Each of the four subject groups received an even distribution of the 8 different types of items. 
Nonword targets were constructed, and were similarly assigned to 12 different context string pairs that were constructed according to the same criteria as the word-item pairs. Twelve "verb"/"noun" nonword pairs, such as FABLORATES/ FABLORATION, were constructed; these pairs were comparable to the verb/noun word pairs in all superficial respects. All the "verb" nonwords had one of the suffixes [-ate], [-ize], or [-ify], followed by the [-s] morpheme. All the "noun" nonwords were formed by adding the suffix [-ion] to the verb. Twelve "adjective"/"adverb" pairs, such as SERICAL/SERICALLY, were constructed on the model of the word pairs. All the "adjective" nonwords ended in [-able], [-ous], [-full], or [-al]. The "adverb" nonwords were formed by adding $[-1 y]$ to the "adjective" nonwords.

As in Experiment 1, half the target items seen by the subject were words, and half were nonwords. Of the word items, half were fillers constructed so that the target word was a natural continuation of the context string (and usually a natural completion as well). ${ }^{6}$

The items were presented in different pseudorandom orders to different subjects. The entire randomized set of 208 items was divided into two equal blocks, each preceded by 10 warm-up items. There was also an initial block of 30 representative practice items.

Procedure. The procedure was identical to that of Experiment 1 , with one modification. An initial execution of this experiment using the Experiment 1 presentation rate of $200 \mathrm{msec} /$ word revealed only hints of the expected effects. A careful look at the data suggested that many subjects were falling behind in their reading of the context strings, particularly for the longer ones. Since they had not reached the end of the string when the target word appeared, their RTs did not show an effect of syntactic context. The somewhat greater length and complexity of Experiment 2 materials might, therefore, account for the lack of differences among conditions in Experiment 2.

The presentation rate for Experiment 2 was slowed to $300 \mathrm{msec} /$ word $(200$ words $/ \mathrm{min}$ ), the target word still appearing $400 \mathrm{msec}$ after the last word of the context string. The delay preceding the target word was much less noticeable than at the faster presentation rate, but the subjects still had no difficulty in identifying which word was the target of their lexical decision. The entire experiment took $.5 \mathrm{~h}$.

\section{Results and Discussion}

The overall error rate (including filler items), was 3.9\%. RTs more than two standard deviations above the subject's mean were replaced with that subject's cutoff value.

Items With Noun and Verb Targets. Table 2 shows the results for materials such as are shown in Example 3.

Table 2

Experiment 2 (Word Items, Verb/Noun Targets): Reaction Times (RTs) (in Milliseconds) as a Function of Syntactic Category of Target and Context-Final Word

\begin{tabular}{lllllll}
\hline & \multicolumn{4}{c}{ Target } \\
\cline { 2 - 3 } $\begin{array}{c}\text { Context-Final } \\
\text { Word }\end{array}$ & \multicolumn{2}{c}{ Verb } & & \multicolumn{2}{c}{ Noun } & \\
\cline { 2 - 3 } \cline { 5 - 6 } & RT & PE & & RT & PE & Mean \\
\hline Noun & 660 & 9 & & 714 & 7 & 685 \\
Verb & 706 & 10 & 673 & 7 & 690 \\
Mean & 683 & & 694 & & \\
\hline
\end{tabular}

Note-PE = percent error.
The results were as predicted: The syntactically illegal VV case and the syntactically nonpreferred NN case yielded higher RTs than did the syntactically preferred $\mathrm{VN}$ and $\mathrm{NV}$ cases. The interaction in a $2 \times 2$ analysis of variance was significant $\left[\min \mathrm{F}^{\prime}(1,43)=8.7\right.$, $p<.01]$. Neither main effect approached significance. Errors, although frequent in this set of data, were evenly distributed over the four cells.

The absence of a main effect of target type in this experiment was somewhat surprising, given that the verb targets were systematically shorter and more frequent than the noun targets. Although these differences were not great, one might have expected a faster time for the verb targets. The absence of a main effect of target type could simply reflect no difference in the recognition time for the target forms, or it could represent an interaction with sentence contexts canceling out length and frequency effects.

A control experiment was run to address this possibility. Two additional groups of 10 subjects performed a simple lexical decision task on the targets of Experiment 2, without sentence contexts. Once again, no subject saw both TRANSLATES and TRANSLATION. The verb and noun targets did not differ in this baseline condition either, indicating no significant difference between these verbs and nouns in recognition time, despite their frequency and length differences.

The predicted interaction effect, taken together with the results of Experiment 1, provides good evidence for effects of syntactic context on lexical decision times: The structure of an incomplete sentence interacts with the grammatical category of the next word, as measured by RT to accept or reject the target letter string. This was observed with two completely different pairs of syntactic types in the two experiments.

The very close semantic relation of the members of target word pairs (such as TRANSLATES/TRANSLATION) in Experiment 2 makes a semantic explanation of the results highly unlikely. Any influence of the sentence context on the meaning of TRANSLATES should be equally an influence on the meaning of TRANSLATION. Thus, the fact that the results for the two words differed can most plausibly be attributed to their syntactic category, and, in turn, the influence on the decision times must have derived from aspects of the syntactic processing of the sentence contexts.

The results for the $\mathrm{NN}$ case are particularly interesting. The VV case (e.g., "The towers on the horizon indicate that the barriers isolate TRANSLATES") is extraordinarly difficult to complete. It is no surprise that the parsing system balks at the word TRANSLATES in this case. However, good syntactic completions are available for all three of the other cases, including the crucial NN case. The finding of an elevated lexical decision time for the NN case is good evidence that we were tapping a real-time processing phenomenon; the NN case is more difficult to process than the VN and NV cases, even though the syntactic structures that result from successful processing are equally acceptable. 
Finally, we note that the affixal marking of grammatical category on the nonwords did not produce any significant effect. The derivational markings of nonwords as nouns and verbs did not interact with fragment type. Nonwords marked as adjectives and adverbs showed no interaction with fragment type either. ${ }^{7}$

Items With Adjective and Adverb Targets. Table 3 shows the results for materials such as are shown in Example 4.

The prediction was that the adjective-after-noun cell (version NA) would show an elevated RT relative to the other three cells. No hint of this effect was visible, and the interaction in a $2 \times 2$ analysis of variance was far from significant. ${ }^{8}$ Neither main effect approached significance. (As with the noun and verb targets, the adjectives and adverbs did not differ in the lexical decision task in isolation either.) More errors occurred in VA and NR versions than in the other two versions, but this effect was far from significant, and has, in any event, no sensible explanation. The contrast in the intuitive acceptability of the adjective in the two sentence contexts seems as great as the contrasts for the noun and verb targets, so the failure to find an effect is puzzling.

One might seek to explain this in terms of some general claim about the salience of adjectives and adverbs as compared with nouns and verbs. We know, for example, that in recall tasks, modifiers are less likely to be reported than are the verbs and nouns that represent the essential predicate-argument relations of the sentence (see, e.g., Perfetti \& Goodman, 1971). Mehler, Segui, Pittet, and Barriere (1978) provided strong evidence that this effect applies even for immediate report when sentences are presented by RSVP procedures.

A more interesting specific possibility is that the parsing system is predicting heads of phrases. (The head of a phrase is, roughly, the single word of which all other words in the phrase are arguments or modifiers.) In both Experiment 1 and the first section of Experiment 2 , the verb and noun targets functioned as the heads of the grammatical constituents that the parser can predict as of the last word of the context string. In particular, consider the items shown in Example 5, which represent the noun- and adjective-target items of Experiment 2.

Table 3

Experiment 2 (Word Items, Adjective/Adverb Targets): Reaction Times (RTs) (in Milliseconds) as a Function of Syntactic Category of Target and Context-Final Word

\begin{tabular}{|c|c|c|c|c|c|}
\hline \multirow{3}{*}{$\begin{array}{l}\text { Context-Final } \\
\text { Word }\end{array}$} & \multicolumn{4}{|c|}{ Target } & \multirow[b]{3}{*}{ Mean } \\
\hline & \multicolumn{2}{|c|}{ Adjective } & \multicolumn{2}{|c|}{ Adverb } & \\
\hline & RT & PE & RT & $\mathrm{PE}$ & \\
\hline $\begin{array}{l}\text { Noun } \\
\text { Verb }\end{array}$ & $\begin{array}{l}672 \\
648\end{array}$ & $\begin{array}{r}8 \\
13\end{array}$ & $\begin{array}{l}698 \\
676\end{array}$ & $\begin{array}{r}13 \\
6\end{array}$ & $\begin{array}{l}685 \\
662\end{array}$ \\
\hline Mean & 660 & $\cdot$ & 687 & & \\
\hline
\end{tabular}

Note $-P E=$ percent error.
Example 5 a. VN The towers on the horizon indicate that the barriers isolate TRANSLATION

b. VA The towers on the horizon indicate that the barriers isolate HAPPY

c. NN The crowd near the church indicates that an inportant funeral TRANSLATION

d. NA The crowd near the church indicates that an important funeral HAPPY

After the verb "isolate," the parser can predict a noun phrase: TRANSLATION can function as the head of that noun phrase, but HAPPY, although a legal part of the noun phrase, cannot function as the head. This might explain why TRANSLATION is recognized faster in version VN than in version NN, whereas HAPPY is recognized at the same speed in versions VA and NA.

There is another difference between the items used to test nouns and verbs and those used to test adjectives and adverbs. This is the fact that, although the adjective and adverb targets provide good continuations for the fragments, they do not constitute a completion of the fragment as a sentence. In contrast, the noun and verb targets may, by somewhat implausible construal, form sentence completions. Although not a likely account, ${ }^{9}$ a proper comparison of the adjective/adverb cases with the noun/verb cases requires that this factor be controlled. The issues affecting tests of adjectives as targets were addressed in Experiment 4.

Finally, there is a methodological point that applies to these findings and to those of Experiment 1 as well. This is the possibility that the syntactic context effects reflected very local transitional probabilities between successive grammatical categories. Thus, it could be that the significant effects arose solely because of the relation between the target and the final word of the fragment, rather than reflecting the syntactic analysis of the whole fragment plus target. Experiment 3 addressed this methodological problem.

\section{EXPERIMENT 3}

In Experiment 3, we preserved the local relations between the last context word and the target word that held in Experiment 2, while changing the syntactic structure of the contexts in a way that was expected to produce the opposite RT effect. Two subexperiments (Experiments $3 \mathrm{a}$ and $3 \mathrm{~b}$ ) were run. The stimulus materials for Experiment 3 a were presented to 20 subjects in two subject groups. After these results were examined, the materials of Experiment 3a were modified for Experiment $3 \mathrm{~b}$. These were presented to 20 additional subjects, again in two subject groups. Three of the 40 subjects had participated in Experiment 2, over 6 months earlier. 


\section{Method}

Subjects. MIT undergraduate volunteers were paid for their participation. All were native speakers of American English. Twenty subjects were run in Experiment 3a. Three subjects were replaced because of obvious inattention to the task; three were replaced due to having error rates greater than $10 \%$; one was replaced due to having an RT standard deviation of greater than $250 \mathrm{msec}$. None exceeded the mean RT cutoff of $850 \mathrm{msec}$ The overall error rate (including filler items) was $3.3 \%$. Twenty subjects were run in Experiment $3 b$. Six were replaced due to having mean RTs greater than $850 \mathrm{msec}$ or RT standard deviations greater than $250 \mathrm{msec}$; none exceeded the $10 \%$ error criterion. The overall error rate was $2.7 \%$.

Materials. The entire set of Experiment 3 materials appears in Appendix C. Twelve pairs like that of Example 6 served as experimental materials for Experiment 3a: These were simplified to 12 pairs like Example 7 for Experiment $3 b$ :

$\begin{array}{lll}\text { Example } 6 & \text { a. NV } & \begin{array}{l}\text { *The students decided that they would } \\ \text { give their teacher ROTATES } \\ \text { The students decided that they would } \\ \text { give their teacher ROTATION } \\ \text { Example } 7\end{array} \\ \text { a. Nhe students gave to their teacher } \\ \text { ROTATES } \\ \text { b. NN students gave to their teacher } \\ \text { ROTATION }\end{array}$

All the fragments used in Experiment $3 a$ end with a string consisting of a verb (such as "give") that can support an indirect object construction, followed by a singular noun phrase two or three words long and ending in a singular noun. The fragments for Experiment 3a were constructed to induce, on semantic grounds, the indirect-object reading of the NP at the end of the fragment, thus requiring another NP at the target position to fulfill the direct-object function. The fragments used in Experiment $3 \mathrm{~b}$ are shorter overall and do not rely on semantic influence to induce the indirect-object analysis of the fragmentfinal NP; it is overtly marked as the object of a preposition (either one introducing an indirect object or a benefactive). Hence, the target noun can be assigned to the direct-object NP required by the verb.

Note that for both Experiments 3a and 3b, the local relation between the fragment-final word and the target word was the same as in Experiment 2; a noun was followed by either a verb or another noun. In Experiment 2, the effect was a lower RT for the verb target. If the effects of the context string were strictly local, we would expect to see the same outcome here. If, however, integration were over the full string, we would expect the opposite: lower RT for the noun target.

The target words used were the same as those in Experiment 2 , and were, as before, semantically unexpected continuations. The experimental items were embedded in a larger set including those for Experiment 4, filler items, and items from other experiments not reported here. The full stimulus set seen by any given subject consisted of 288 items, half of which were presented with nonword targets; of the remaining 144 presented with word targets, one half of these made complete natural sentences. The items were presented in different pseudorandom orders to different subjects. The entire randomized set of 288 items was divided into three equal blocks, each preceded by 5 warm-up items. There were also 30 representative practice items presented as an initial block.

Procedure. The procedure was the same as for Experiment 2, using a presentation rate of $300 \mathrm{msec} /$ word. The experiment took approximately $40 \mathrm{~min}$ to complete.

\section{Results and Discussion}

Table 4 shows the RT and error results for Experiments $3 \mathrm{a}$ and $\mathbf{3 b}$.
Table 4

Experiments 3a and 3b: Reaction Times (RTs) (in Milliseconds) as a Function of Syntactic Category of Target

\begin{tabular}{crrrrr}
\hline & \multicolumn{3}{c}{ Target } \\
\cline { 3 - 5 } & \multicolumn{2}{c}{ Verb } & & \multicolumn{2}{c}{ Noun } \\
\cline { 3 - 5 } Experiment & RT & PE & & RT & PE \\
\hline $3 a$ & 709 & 18 & 732 & 12 \\
3b & 728 & 7 & 665 & 3 \\
\hline
\end{tabular}

Note-PE = percent error.

Consider first the outcome for Experiment 3a. RTs showed no significant difference between the conditions ( $p>.3$ for both subject and item analysis). The more striking aspect of these results was the error rate, which averaged $14.6 \%$. This was far above the $3.3 \%$ error rate for these subjects over all the items they saw. It was also higher than the $9.1 \%$ error rate shown for these very same target words in Experiment 2. The difference in error rate between the $\mathrm{NN}$ and $\mathrm{NV}$ versions is not significant.

These results do not provide much help with the question of local transition versus full fragment analysis as the causal factor in RT differences. The high error rate is likely to be an indication of difficulty in processing the fragment, which interfered with the accuracy of the lexical decision task. It is also possible that the semantic constraints did not effectively constrain analysis of the NP following the verb, thus permitting assignment of that NP to the direct-object slot and removing the basis for an NP prediction at the target position. ${ }^{10}$

On the basis of these assumptions, the contexts in Experiment $3 \mathrm{~b}$ were modified to provide a stronger basis for the prediction of a noun phrase, and to be easier to process. In contrast with Experiment $3 a$, the fragments used in Experiment $3 \mathrm{~b}$ contain object-taking verbs (not necessarily ones that can take an indirect object) followed by a prepositional phrase. The only steps that must be performed to obtain a noun prediction are (1) the recognition of the verb as one requiring an object, and (2) the recognition that the prepositional phrase cannot function as that object. No semantic or pragmatic computations are required. The fragments used in Experiment $3 \mathrm{~b}$ were also shorter than those used in Experiment 3a.

The bottom line of Table 4 shows the results for Experiment $3 \mathrm{~b}$. The noun targets were recognized $63 \mathrm{msec}$ faster than the verb targets, and the difference was significant $\left[\min F^{\prime}(1,30)=4.2, p<.05\right]$. The error rate in Experiment $3 \mathrm{~b}(5.0 \%)$ was dramatically lower than the Experiment 3a error rate $(14.6 \%)$, and that difference was significant $\left[\min F^{\prime}(1,25)=4.8, p<.05\right]$.

The finding of faster RTs to the noun targets in this experiment is inconsistent with a local-transition hypothesis. The local relations between the fragmentfinal word and the target are unchanged from Experi- 
ment 2, yet the RT effect is reversed. We conclude that the influence on RT derives from an analysis encompassing at least the verb phrase of the context fragment.

\section{EXPERIMENT 4}

Experiment 2 raised questions about the mechanisms responsible for the different RTs observed for the noun and verb targets in compatible and incompatible syntactic environments. These questions arose because of the failure of adjectives to show effects similar to those of nouns and verbs. We wished to know whether the effects observed in the first two experiments are specific to nouns and verbs because of some general salience factor associated with those categories, or whether a more interesting construal in terms of specific phrasal roles accounts for the differences observed. Experiment 4 provided test sentences in which an adjective target functioned as the head of a predictable adjective phrase. In contrast, the adjective targets in Experiment 2 were legal and natural continuations of the context, but never were they heads. In Experiment 4, we also controlled for the factor of sentence-completion possibility (i.e., whether the target word could end a sentence), which was confounded with the adjective/adverb treatment in Experiment 2.

\section{Method}

Subjects. Forty MIT undergraduate volunteers were paid for their participation. These were the same subjects that had participated in Experiments $3 \mathrm{a}$ and $3 \mathrm{~b}$.

Materials. The entire set of Experiment 4 materials is shown in Appendix D. Sixteen quadruples like that shown in Example 8 served as the experimental item sets:

$\begin{array}{rrl}\text { Example } 8 & \text { a. RA } & \begin{array}{l}\text { The interesting clock seems very TOL- } \\ \text { ERABLE } \\ \text { The interesting clock seems very RALO- } \\ \text { bALET } \\ \text { bour visiting friend should enjoy TOL- }\end{array} \\ \text { c. VA } & \begin{array}{l}\text { Younde } \\ \text { ERABLE } \\ \text { dour visiting friend should enjoy RALO- } \\ \text { RALET }\end{array}\end{array}$

The $\mathbf{R}$ context of Examples $8 \mathrm{a}$ and $8 \mathrm{~b}$ ( $\mathbf{R}$ stands for adverb and $X$ for nonword) ends with a verb that frequently takes adjective complements, followed by a degree adverb. Although degree adverbs can introduce adverb as well as adjective phrases, it seems reasonable to assume that an adjective phrase can be predicted by the end of the context. The $V$ context of Examples $8 \mathrm{c}$ and $8 \mathrm{~d}$ ends after an object-taking main verb. As in Experiment 2 , the grammar allows prediction of a noun phrase, of which the adjective TOLERABLE can be a legal part but cannot be the head.

In version RA, TOLERABLE is the head of the predictable adjective phrase. Versions RX and VX consist of the same contexts matched with a nonword target. These provide a baseline measure of the processing difficulty of the two fragments.

\section{Results and Discussion}

The effect we wish to measure for this experiment is the difference of the RA and VA versions, each first corrected for an effect of the specific fragment by sub-
Table 5

Experiment 4: Reaction Times (RTs) (in Milliseconds) as a

Function of Target (Word or Nonword) and Context-Final Word

\begin{tabular}{|c|c|c|c|c|c|}
\hline \multirow{3}{*}{$\begin{array}{c}\text { Context-Final } \\
\text { Word }\end{array}$} & \multicolumn{4}{|c|}{ Target } & \multirow[b]{3}{*}{ Mean } \\
\hline & \multicolumn{2}{|c|}{ Adjective } & \multicolumn{2}{|c|}{ Nonword } & \\
\hline & RT & $\mathrm{PE}$ & RT & $\mathrm{PE}$ & \\
\hline Adverb & 618 & 3 & 668 & 2 & 643 \\
\hline Verb & 659 & 5 & 675 & 2 & 668 \\
\hline Mean & 639 & & 672 & & \\
\hline
\end{tabular}

Note-PE = percent error.

tracting its nonword control. As a formula, this "effect score" is (RA-RX) - (VA-VX), which is equal to the interaction effect in a two-way analysis of variance, with fragment type as one factor and target type (word or nonword) as the other. Table 5 shows the results.

The interaction effect is $34 \mathrm{msec}$, and is significant for the subject analysis $[F(1,38)=6.4, p=.016]$ but marginal for the item analysis $[\mathrm{F}(1,15)=3.3, \mathrm{p}=.089]$. An examination of the "effect score" for each item revealed a single item with a score of $+196,2.6$ standard deviations from the mean. This item may be excluded from the analysis on the grounds that it is grossly unrepresentative of the pool of items. Just to be somewhat conservative, the item with the lowest effect score $(-155)$ was also eliminated along with this offending item. With the two extreme items eliminated, the effect is significant $\left[\mathrm{min} \mathrm{F}^{\prime}(1,33)=4.7, \mathrm{p}<.05\right]$. The adjective target yields a lower RT when it is the head of a predicted adjective phrase.

The main effects in this analysis of variance are of no particular theoretical interest, but both are near significance. The effect of target type (word vs. nonword) is significant for subjects $[\mathrm{F}(1,38)=8.8, \mathrm{p}=.0052]$, but not for items $[F(1,13)=2.2, p=.16]$. The effect of context type is significant for both subjects $[F(1,38)$ $=15.6, p=.0003]$ and items $[F(1,13)=5.6, p=.034]$, but not quite for $\min F^{\prime}\left[\min F^{\prime}(1,24)=4.1, p<.10\right]$.

The faster RT to the adjective target when it is the head of a predicted phrase lays to rest the hypothesis that a general salience factor associated with grammatical category membership accounts for the adjective results in Experiment 2. This suggests the more interesting possibility that phrasal role is indeed the significant factor. To clearly establish this hypothesis would, of course, require a number of additional tests.

\section{GENERAL DISCUSSION}

Lexical decision for words in sentence contexts can show purely syntactic effects on the recognition time for noun, verb, and adjective targets. The effects for nouns and verbs were observed for two different syntactic environments: In Experiment 1, the determining con- 
texts ended in modal verbs and prepositions, whereas in Experiment 2, they ended in main verbs and singular NPs. Adjective effects were observed only for a single context-that ending in a degree adverb. Contexts ending in a verb showed no effect for adjective targets. We have suggested that this may be accounted for by the hypothesis that the effects found in these experiments arise from a predictive mechanism that might either be characterized as "search for phrasal heads" or a topdown prediction of the phrasal categories for which the target words may serve as heads.

A semantic or pragmatic account of the results is implausible because the lexical decision targets were of extremely low (zero) predictability with respect to the interpretations of the context fragments. Such accounts are rendered even more unlikely by the further feature of Experiment 2 in which minimal pairs such as TRANSLATES/TRANSLATION were used. In such circumstances, semantic or pragmatic constraints should be equivalently useful (or equivalently useless).

One of the most interesting features of the results showing an influence of syntactic structures on lexical processing efficiency is the indication that they are a byproduct of the operation of a "human parser"-that is, a system that has processing strategies yielding degrees of difficulty in coping with structures that are all potentially well-formed. Put most neutrally, our results show that some process within subjects slows responses whenever the target word is "odd" with respect to the preceding context. We have ruled out oddness based on semantic or pragmatic information. Syntactic construals of oddness might be of two sorts-those based on the formal notion of grammaticality, and those based on the computational notion of parsing procedures. The notion of grammaticality would account for the results of Experiment 1. The cases yielding slow RTs there consisted of a modal verb followed by a noun, and a preposition followed by a main verb. In both cases, the item could not be completed grammatically. It would also account for the cases in Experiment 2 in which a main verb was followed by another main verb. However, it would not account for the second case in Experiment 2, in which a noun was followed by another noun. This construction was perfectly grammatical, yet it yielded an RT elevated to the same degree as the others. This is important to the plausibility of our argument that the failure in Experiment 2 to find an effect using adjective and adverb targets arose because of the phrasal role played by the targets. If absolute grammatical acceptability were the determinant, one would have to predict no difference for the adjectives and adverbs that were used in Experiment 2 (which is what we observed), for the succession noun-adjective does have a licit continuation. However, it is one that is low on the priority scale for plausible parsing strategies. It is both the fact that Experiment 4 showed an effect of adjective targets in adjective phrases and the fact that absolute grammaticality was not the determining factor in the sub- jects' performance that permits the inference that a parsing strategy based on phrasal heads may be at issue.

We noted two versions of the hypothesis that processing of phrasal heads is facilitated. These are difficult to distinguish without a better understanding of the mechanisms that generated the effects that we observed. For example, it may be that the effects arose from a confirmation procedure that tested for the satisfaction of the parsing constraints imposed by the predicted phrasal type. Such a procedure might be completed upon the presentation of a phrasal head, but not by presentation of other phrasal elements. In contrast, one might suppose that the lexical search aspects of the recognition of the phrasal heads is facilitated by the target word's correspondence to the required grammatical category. This latter account presumes that entry into the lexicon can be guided by category, whereas the former account makes no such presumption. As we noted in the introduction, such evidence as we have for the use of syntactic category in directing lexical access for recognition is negative.

We do have some weak evidence that lexical retrieval is a necessary feature of the processes that underlie our results. The failure to find any effect of context on rejection times for nonwords with endings similar to those of the target words argues that the relevant property of the target words is not simply their surface affixal marking. It is at least conceivable that a procedure for evaluating the acceptability of lexical inputs for a given phrasal analysis could be stated using just the affixal evidence. However, we cannot place too much reliance on this observation as a way of deciding between a claim that lexical search is facilitated by these contexts, and the claim that some form of parsing filter is at work. This is because the nonword effects may simply be too slow to be responsive to the parsing mechanism before a lexical search determines that the form input is not present. That is, a procedure that isolates affixal information by interaction with stored lexical information may be required in order that the parsing procedures are executed soon enough to influence RTs.

The final matters we wish to place some emphasis on concern the role of meaning factors in the effects we have reported. We have commented on our effort to design the experiments in such a way as to render ineffective those features of language processing that make use of what a listener or reader knows of plausible circumstance-uses that are of undoubted import in the effective real-time exercise of our language capacity. The fact that our experiments ruled these variables out of play, and nonetheless revealed a significant effect of syntactic constraint on lexical recognition performance, does not prove, of course, that this is the way matters work with respect to semantic and syntactic processes in the normal communicative situation. Still, there are also some positive indications that this insulation between the two sorts of processes is not an artificiality 
of our control measures: When we sought to manipulate "expectation" of phrasal type in Experiment 3 by semantic constraint, we did not succeed; when virtually the same effort was repeated with syntactic constraint, the lexical decision effects were observed. Furthermore, there is similar import in observations from the experiments by Mehler et al. (1978): The poorer RSVP report levels they observed for adjectives that are noun modifiers was not affected by the semantic relation between noun and adjective. That we should consider the results they report as bearing on processes similar to those we have attempted to investigate is further indicated by their finding that RSVP performance significantly improved for adjectives that were not used as modifiers-an outcome that presages the results of our Experiment 4, in which adjectives serving as phrasal heads produced a significant influence on lexical decision.

We have reported evidence for a systematic syntactic mechanism that affects lexical decision performance, and suggested that it may be construed in terms of the role of heads of phrases in parsing processes. That construal makes all the more striking the possibility of a real insulation of such a process from direct semantic intervention. Heads of phrases are plausible foci of interpretation if any individual element of a phrase is. Direct investigation of the role of semantic constraints in parsing processes will be required to determine the merits of any such claims about human sentence processing.

\section{REFERENCE NOTES}

1. Prather, P., \& Swinney, D. Some effects of syntactic context upon lexical access. Paper presented at the meeting of the American Psychological Association, August 1977.

2. Oden, G., \& Spira, J. Influence of context on the activation and selection of ambiguous word senses (Wisconsin Human Information Processing Program No. 6). Madison, Wis: University of Wisconsin, 1978.

\section{REFERENCES}

FAY, D. Some investigations of grammatical category in performance devices. Doctoral dissertation, University of Texas at Austin, 1975.

Fischler, I., \& Bloom, P. A. Rapid processing of the meaning of sentences. Memory \& Cognition, 1980, 8, 216-225.

Forster, K. I. Visual perception of rapidly presented word sequences of varying complexity. Perception \& Psychophysics, $1970,8,215-221$.

Forster, K. I. Levels of processing and the structure of the language processor. In E. Walker \& W. Cooper (Eds.), Sentence processing. Hillsdale, N.J: Erlbaum, 1979.

Forste r, K. I. Priming and the effects of sentence and lexical contexts on naming time: Evidence for autonomous lexical processing. Quarterly Journal of Experimental Psychology, 1981, $33 A, 465-495$.

Forster, K. I., \& Bednall, E. Terminating and exhaustive search in lexical access. Memory \& Cognition, 1976, 4, 53-61.

Goodman, G., McClelland, J., \& Gibbs, R. The role of syntactic context in word recognition. Memory \& Cognition, 1981 , 9, 580-586.

Kučera, H., \& Francis, W. N. Computational analysis of present-day American English. Providence, R.I: Brown University Press, 1967.
Lukatela, G., Kostic, A., Feldman, L. B., \& Turvey, M. T. Grammatical priming of inflected nouns. Memory \& Cognition, $1983,11,59-63$.

Mehler, J., Sequi, J., Pittet, M., \& Barriere, M. Strategies for sentence comprehension. Journal of Psycholinguistic Research, 1978, 7, 3-19.

Mille R, G. A. Decision units in the perception of speech. IRE Transactions on Information Theory, 1962, IT -8, 81-83.

Mille R, G. A., \& IsARD, S. Some perceptual consequences of linguistic rules. Journal of Verbal Learning and Verbal Behavior, 1963, 2, 217-228.

Perfetti, C., \& Goodman, D. Memory for sentences and noun phrases of extreme depth. Quarterly Journal of Experimental Psychology, 1971, 23, 22-33.

Seidenberg, M., Tanenhaus, M., Leiman, J., \& Bienkowski, M. Automatic access of the meanings of ambiguous words in context: Some limitations of knowledge-based processing. Cognitive Psychology, 1982, 4, 489-537.

Swinney, D. The structure and time course of information interactions during speech comprehension: Lexical segmentation, access and interpretation. In J. Mehler, S. Franck, E. Walker, \& M. Garrett (Eds.), Perspectives on cognitive representations and processes. Hillsdale, N.J: Erlbaum, 1983.

\section{NOTES}

1. Since this paper was written, a finding by Lukatela, Kostic, Feldman, and Turvey (1983) has been called to our attention. They found a significant syntactic effect on lexical decision using preposition-noun pairs in Serbo-Croatian. Their result, using a stimulus pair similar to that of Goodman et al., suggests that a nonstrategic effect of this type may be obtainable for English as well.

2. For instance, COMPETE and ENTRIES are a matched verb and noun. ENTRIES has at least two meanings (entries into a building, entries into a chart), but it is acceptable because in all its meanings it is used as a noun.

3. In addition, each subject saw 12 word and 12 nonword items from a pilot experiment not discussed here.

4. For all min $F^{\prime}$ computations in this paper, subjects (or items, for the item analysis) are crossed with both the context and target variables. Each subject's data are mean corrected for his or her mean on the entire 208 items (including fillers). This has no effect on the subject analysis, but reduces variability due to subjects within the item analysis. For each analysis, errors were replaced with the appropriate cell mean for that analysis.

5. Being related by derivational morphology does not guarantee that two words have the same meanings. For example, OCCUPIES is a verb meaning roughly "move into" or "take up," and the noun OCCUPATION has corresponding meanings as in "Germany's occupation of Poland was brutal." But OCCUPATION has another meaning, "a job," for which the verb OCCUPIES has no corresponding meaning. For this experiment, pairs that did share all their meanings were chosen.

6. The remaining half of the word items included materials from pilot experiments not discussed here.

7. In neither case does the statistical interaction in the $2 \times 2$ analysis of variance show any hint that a (conceptual) interaction between sentence context and nonword category information has occurred. This argues against one kind of explanation for the results obtained with noun and verb word targets in this experiment. If that result were due to an interaction of sentence context with the surface forms of categorydetermining suffixation (such as "ate," "ion," or "ify"), then one would expect to observe such an interaction with nonwords as well. For the syntactic force of such suffixes to be felt in this task, they apparently must occur on real words.

8. A direct comparison of the NA cell with the other three cells does not seem appropriate given the requirement that main effects of context type and target type be factored out. In any case, the direct comparison is also far from significance.

Errors are evenly distributed over the four cells in both 
nonword cases. For RTs, the main effect of context type is far from significant, but the main effect of target type is significant for the "verb"/ "noun" targets $\left[35 \mathrm{msec}\right.$, min $F^{\prime}(1,44)=5.6$ $\mathrm{p}<.05]$, and approaches significance for the "adjective"/ "adverb" targets $\left[32 \mathrm{msec}, \min \mathrm{F}^{\prime}(1,48)=3.7, \mathrm{p}<.10\right]$. In both sets of results, the longer nonword target requires more time to reject than does the shorter nonword target. This effect might well be due to the differences in morphology, rather than to the length difference per se. If so, it may have a bearing on the role of word morphology in lexical access.

9. Note that these are "good completions" only in the very narrow sense of being the correct part of speech. The targets that do determine complete sentences provide completions that are nearly always horrendous pragmatically, and of ten violate semantic and strict subcategorization restrictions as well. However, as the paradigm is set up, no words are ever presented after the target word, and in the filler items, the target word does in fact complete a syntactically, semantically, and prag. matically natural sentence of English. The fillers were constructed in this way to encourage subjects to try to process the target word as part of the context strings in the experimental items, but it may have encouraged in addition a completion strategy.

10. There may be an interesting relationship between the processing difficulty and the assignment of the indirect object NP to the direct object slot. The semantic problems that must arise because of that assignment might be producing a mild "garden path" that disrupts lexical decision accuracy.

Appendix A

RT for

Target

$\mathrm{V} \mathbf{N}$

Item

703772 The man spoke but could COMPETE/ENTRIES

691647 Just at the time of COMPETE/ENTRIES

593554 Enforcement of the law could LOCATE/ERRORS

671661 Nothing can be said against LOCATE/ERRORS

746821 Life in dorms at Harvard would REPRESENT/QUALITIES

720627 Bill told me to go without REPRESENT/QUALITIES

698624 Everyone interested in this course can GOVERN/HABITS

731588 The cold morning wind blew through GOVERN/HABITS

724732 If your bicycle is stolen, you must FORMULATE/BATTERIES

692683 For now, the happy family lives with FORMULATE/BATTERIES

591647 The seller agrees that the buyer shall REALIZE/DEGREES

626681 Suppose that the criminal escaped from behind REALIZE/DEGREES

592536 In the writings of Karl Marx, we can BRING/FACTS

667537 There is only one person in charge of BRING/FACTS

694857 Within the framework of this theory, it should ORGANIZE/PASSAGES

675764 There is an old Norwegian folk tale about ORGANIZE/PASSAGES

569644 When you buy a car, the owner's manual will BELIEVE/ACTIONS

589642 In the morning, the dog awakened and stared across BELIEVE/ACTIONS

676763 The essential beauty and order of the universe might ENTER/UNITS

738678 The nervous student closed his eyes and whispered into ENTER/UNITS

608833 If the warhead is detected during its flight, it may ADMIRE/OCEANS

773780 Israel's national airline will open a commercial air route between ADMIRE/OCEANS

616723 In modern Japan elegance is sought in simple things, and this should CONTINUE/PURPOSES

801767 A man under the influence of this strange new drug passes into CONTINUE/PURPOSES

Experiment 1b Materials

554662 All people who agree should COMPETE/ENTRIES

911723 The book was lying on COMPETE/ENTRIES

628709 The American political system can LOCATE/ERRORS

692573 The former general concluded with LOCATE/ERRORS

717703 All the players agreed they would REPRESENT/QUALITIES

810686 Nobody knew that the office of REPRESENT/QUALITIES

692778 A law requiring mandatory sentences could GOVERN/HABITS

797683 There is an interesting similarity between GOVERN/HABITS 
Appendix A (continued)

743713 Today, the concern of all people must FORMULATE/BATTERIES

775686 New York needs to deal vigorously with FORMULATE/BATTERIES

703825 Soldiers who refused to obey orders could REALIZE/DEGREES

710689 The typical alcoholic is apparently sincere in REALIZE/DEGREES

713944 The simple satisfaction of physical labor will ORGANIZE/PASSAGES

689625 The company's decision affects all trains from ORGANIZE/PASSAGES

636603 Dinner at a fine restaurant in Boston would BRING/FACTS

739612 This incident brings me to the method by BRING/FACTS

669573 The governor also believes that the state should BELIEVE/ACTIONS

674641 It is reported that a tornado swept through BELIEVE/ACTIONS

636766 After you have added the three eggs, you must ENTER/UNITS

559561 My grandmother looked at the floor, her hands beneath ENTER/UNITS

663644 There are ways in which both men and women might CONTINUE/PURPOSES

734826 The universe that we have learned about spreads out from CONTINUE/PURPOSES

669794 If a ball is set on an inclined plane, it will ADMIRE/OCEANS

850762 Before the child got into bed, he put his shoes near ADMIRE/OCEANS

Note-Throughout these appendixes, $R T$ s are from the item analysis. $R T$ means in text are an average of item and subject analysis means. Due to differences in error replacement, these values differ slightly.

Appendix B

RT to Target

V N Adj Adv

Item

Experiment 2: Word Items

$\begin{array}{llll}725 & 693 \quad 675 \quad 738 \quad \text { A very large pine forest }\end{array}$

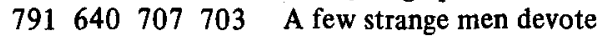

EXPELS/EXPULSION/INFREQUENT/INFREQUENTLY

800834710700 When an airplane reports to the control tower that its right engine

757704703687 If the situation at home becomes so bad that the boys accuse

BETRAYS/BETRAYAL/FOOLISH/FOOLISHLY

674798722765 The angry woman stormed out, and now her exhausted husband

719731714779 The great ship broke apart, and now the survivors prevent ROTATES/ROTATION/SYSTEMATIC/SYSTEMATICALLY

664617710765 The professor speaks gently, but a terrified student

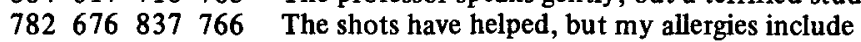

DISCOVERS/DISCOVERY/VAST/VASTLY

624709650621 The tallest building near the hotel

$639612536 \quad 610$ Some remote villages now can enjoy

ASSURES/ASSURANCE/CONTINUOUS/CONTINUOUSLY

$\begin{array}{lllll}748 & 678 & 748 & 750 & \text { I doubt that my small contribution }\end{array}$

702731730709 I doubt that his books characterize

PERSISTS/PERSISTENCE/RIGID/RIGIDLY

631761723813 In a move of great significance, Britain's new parliament

664655759706 To the distress of the opposition, Germany's laws discourage ACCELERATES/ACCELERATION/FAVORABLE/FAVORABLY

513708622601 In this election, the leading candidate

569661547582 In this serial, the women introduce EXISTS/EXISTENCE/SIMILAR/SIMILARLY

$578698791844 \quad$ Some fanatics argue that each case of pollution

$\begin{array}{lllll}757 & 758 & 787 & 835 & \text { Most citizens feel that hard work can replenish }\end{array}$

SUPPRESSES/SUPPRESSION/PERPETUAL/PERPETUALLY 
Appendix B (continued)

702709562686

$\begin{array}{llll}780 & 649 & 528 & 672\end{array}$

$\begin{array}{llll}688 & 710 & 542 & 580\end{array}$

$\begin{array}{llll}723 & 672 & 486 & 558\end{array}$

$587 \quad 648 \quad 651 \quad 595$

$604 \quad 634589532$

$\begin{array}{llll}785 & 709 & 796 & 793\end{array}$

$\begin{array}{lllll}727 & 756 & 798 & 828\end{array}$

$\begin{array}{llll}705 & 638 & 837 & 888\end{array}$

$\begin{array}{lllll}705 & 730 & 801 & 826\end{array}$

$\begin{array}{llll}845 & 799 & 804 & 786\end{array}$

787744716749

$\begin{array}{llll}780 & 768 & 713 & 655\end{array}$

$758743 \quad 668 \quad 646$

$\begin{array}{llll}691 & 735 & 674 & 580\end{array}$

$658646 \quad 625615$

809801854736

$\begin{array}{llll}683 & 651 & 674 & 787\end{array}$

$719850698 \quad 756$

$\begin{array}{llll}683 & 834 & 725 & 758\end{array}$

$744799707 \quad 779$

$\begin{array}{lllll}759 & 860 & 767 & 825\end{array}$

$686 \quad 819682692$

662715649690

$\begin{array}{llll}581 \quad 617 & 720 & 804\end{array}$

$\begin{array}{llll}687 & 783 & 693 & 774\end{array}$

$\begin{array}{llll}647 & 786 & 739 & 822\end{array}$

$\begin{array}{llll}639 & 702 & 722 & 803\end{array}$

$\begin{array}{llll}690 & 734 & 688 & 788\end{array}$

$676722703 \quad 832$
During inventory, the shopkeeper will find that an expensive camera

When proofreading, even famous authors find that the editors modify

GROWS/GROWTH/EASY/EASILY

The crowd near the church indicates that an important funeral

The towers on the horizon indicate that the barriers isolate

TRANSLATES/TRANSLATION/HAPPY/HAPPILY

Accompanied by some elves, a graceful fairy

Unaware of the risks, some people evade

REFLECTS/REFLECTION/SERIOUS/SERIOUSLY

Experiment 2: Nonword Items

A geologist believes that the presence of a valuable mineral

A physicist observed that new studies on the nucleus utilize

IRROLINATES/IRROLINATION/MOMENABLE/MOMENABLY

An estimate of the storage capacity

Her writings on the problem identify

FABLORATES/FABLORATION/MAGNIFUL/MAGNIFULLY

A single piece of fabric

A strong person will attain

PROSURIZES/PROSURIZATION/REPAROUS/REPAROUSLY

Either someone is being funny, or the library's rarest volume

Either stolen goods are appearing, or the city's merchants obtain

DISCULATES/DISCULATION/FOLLAINABLE/FOLLAINABLY

The evidence suggests that the younger defendant

Farm statistics suggest that small farmers cultivate

ISOPIFIES/ISOPIFICATION/BLURKFUL/BLURKFULLY

Despite the advances of the enemy, the small nation's defense

Despite a sharp rise in pressure, the vessel's walls contain

DISTOCIZES/DISTOCIZATION/SERICAL/SERICALLY

History has shown that each legislative session

The custom is that all Republicans replace

CONIORIFIES/CONJORIFICATION/AMPORABLE/AMPORABLY

While conservatives favor a tax cut, at least one liberal

While adults argue about child abuse, more toys could satisfy

TERMORATES/TERMORATION/PRETERNFUL/PRETERNFULLY

Experts say that during an earthquake, every single resident

Henry says that in his opinion, these changes simplify

INTRANIZES/INTRANIZATION/NERCUDICAL/NERCUDICALLY

The press deadline is approaching, but the harried reporter

The promised elections are nearing, but the protests resemble

LUDIFIES/LUDIFICATION/EXARDABLE/EXARDABLY

A mother can sing a lullaby, but her small infant

The energy shortage can be filled, but we must invent

BECEPTIFIES/BECEPTIFICATION/INTER REDIOUS/INTERREDIOUSLY

The detective believes that the desk calendar

The engineer believes that the fans generate

CALSUMIZES/CALSUMIZATION/RELETUAL/RELETUALLY

Appendix $\mathrm{C}$

Experiments $3 a$ and $3 b$

\section{Experiment 3a Experiment $3 b$}

Passing the gift shop reminded the man to send his invalid mother

The man will mail to his invalid mother

$809-4 / 861-3$

724-0/763-0

EXPELS/EXPULSION 
Since it was her birthday, the boss said he would get his secretary

The boss will obtain for his secretary
775-2/852-3
$735-2 / 741-0$
BETRAYS/BETRAYAL

The students decided that they would give their teacher

The students gave to their teacher
699-0/787-1
753-1/624-0
ROTATES/ROTATION

When the new dictator granted his old rival

The dictator should grant to his old rival 697-2/686-0

$740-0 / 648-0$

DISCOVERS/DISCOVERY

After winning the lottery, I decided to buy my daughter

I purchased for my daughter

696-1/821-0 799-0/787-1 PERSISTS/PERSISTENCE

The little girl at the zoo tossed the elephant

The child at the zoo threw to the elephant
659-4/771-1
724-2/725-0
ASSURES/ASSURANCE

With great arrogance the doctor handed the nurse

The doctor is handing to the nurse
740-1/641-0
772-0/702-1
ACCELERATES/ACCELERATION

The druggist asked the clerk to sell the young man

The company has released to the press
620-0/659-0
620-0/584-0
EXISTS/EXISTENCE

The exhausted father agreed to read his young son

The minister was reciting to the dying woman
$781-2 / 665-0$
789-1/626-1
SUPPRESSES/SUPPRESSION

The girl reached across the table to pass her father

The girl is getting for her father
688-5/759-4
791-2/618-1
GROWS/GROWTH

In his speech, the manager wished the retiring staff

The manager has bought for the retiring clerk
669-0/654-1
$660-0 / 607-0$
TRANSLATES/TRANSLATION

The bartender asked the musicians to play the assembled crowd

The musician gave to the assembled crowd $671-0 / 683-1 \quad 662-0 / 568-0$

REFLECTS/REFLECTION

Note-Top context of each pair is from Experiment $3 a$; bottom is from Experiment $3 b$. The slash separates results for the two target words. After the dash are the number of errors (out of 10).

Appendix D

Experiment 4

Hanging from the ceiling, the two strips of flypaper seemed to be very

Swarming out of the cavern, the colony of bats led us to appreciate
$599 / 806$
FOREIGN
$662 / 714$
DOLEIGN

The insides of an automatic banking machine can appear very

The weathered exterior of an old farmhouse can easily hide $576 / 647$ RECENT

$694 / 739$

WACENT

A couple argued, and the man appeared barely

The sun shone, and the small puppy chased
$531 / 606$
FULL
$702 / 622$
FUTE

The chandelier hanging over the table appears to be highly Water dripping from the ceiling convinced the man to fix $614 / 667$ MEANINGFUL $605 / 612$

NEANARDESH

The character trudging past seemed to be extremely People passing by persuaded the workmen to modify
$568 / 614$
WIDE
$664 / 615$
NIRE 
Appendix D (continued)

The pamphlets on the display rack seemed utterly

The new magazines in the library have caused
$582 / 630$
RELIABLI
$647 / 610$
REMIADIT

The interesting clock seems very

Your visiting friend should enjoy
$641 / 749$
TOLERABLE
$612 / 643$
RALORALET

The passengers in the airline terminal seemed to be absolutely

The program's history of large cost overruns serves to complicate
$618 / 620$
SUCCESSFUL
$823 / 824$
INAPESSIRI

Those two people were completely

Some recent authors have described
$647 / 609$
LAZY
$646 / 618$
AMER

Young codfish swim so that they remain absolutely

Migrating geese fly so that they can identify
$788 / 686$
IRRATIONAL
$711 / 804$
INDATACTER
[item rejected]

The mechanism of airplane flight remains very

A knowledge of classical music must include
$581 / 600$
REALISTIC
$663 / 661$
PROMASTIN

Physicists say the first few seconds of the universe were very

Journals now say the ozone layer of the atmosphere rarely receives
$650 / 722$
DELICATE
$658 / 658$
TERICORE

The croutons in the salad appeared to be nearly

The people in that restaurant must try to consume
$607 / 582$
STUPID
$629 / 675$
SPONAD

Scraping off the old paint turned out to be highly

Turning over the rocky soil should be done to remove
$653 / 807$
OBVIOUS
$660 / 701$
RAVIRGE

The use of salt in prepared foods has become highly

The makers of baby food in glass jars also package
$612 / 637$
MODERN
$733 / 668$
LADERN

The old green shirt had become barely

The new plastic tape will actually fasten

648/624 AVAILABLE 621/644 NORSHELON

Note-The slash separates $R T$ values for a given target following the two context strings.

(Manuscript received May 8, 1983;

revision accepted for publication September 11, 1983.) 